\title{
STUDY OF VARIATIONS IN HUMAN PLACENTAL ATTACHMENT OF UMBILICAL CORD AND ITS CLINICAL SIGNIFICANCE
}

\section{Dakshayani. K.R ${ }^{1}$, Rajapur. Parashuram *2.}

${ }^{1}$ Professor and HOD, Department of Anatomy, Mysore Medical College and Research Institute, Mysuru, Karnataka, India.

${ }^{* 2}$ Associate professor, Department of Anatomy, Mysore Medical College and Research Institute, Mysuru, Karnataka, India.

\section{ABSTRACT}

Introduction: The word placenta comes from Latin - flat cake and Greek -"Plakous" which means "flat, slab like." Only eutherian mammals possess placenta. The human placenta is discoid, hemochorial and deciduate which functions as a fetomaternal organ. It is developed from chorion frondosum \& decidua basalis. Abnormalities in the development and site of insertion of the umbilical cord can affect maternal and fetal well-being. The umbilical cord is usually attached near the centre of the placenta. The various types of umbilical cord attachment into the placenta are: central, eccentric, battledore (marginal), velamentous (membranous) and furcate. Hence knowledge about the variations in the placental attachment of umbilical cord is important for clinicians.

Aims and Objectives: The present study is undertaken to study various types of placental attachment of umbilical cord.

Materials and methods: The study was carried out on $10 \%$ formalin fixed 100 normal human placenta collected from department of Obstetrics and Gynaecology, Cheluvamba Hospital for children \& women, Mysore medical college and research institute, Mysuru, Karnataka. The study was carried out in department of Anatomy, MMC\&RI, Mysuru. Study of various types of placental attachment of umbilical cord was done by naked eye observation. The data obtained was tabulated \& statistically analysed.

Observations and Results: Out of 100 placenta observed 68 placenta had central attachment of umbilical cord, 16 placenta had eccentric attachment, 12 placenta had battledore (marginal) attachment and 04 placenta had membranous (velamentous) attachment.

Conclusion: Variation in the placental attachment of umbilical cord is associated with various congenital anomalies. Therefore early prenatal ultrasonographic identification of anomalies helps in reducing risk in maternal and perinatal outcome.

KEY WORDS: Umbilical cord attachments - eccentric, battledore, velamentous, furcate, congenital anomalies, preterm labour.

Corresponding Author: Dr. Rajapur. Parashuram. Associate professor, Department of Anatomy, Mysore Medical College and Research Institute, Mysuru, Karnataka, India.

E-Mail: dakshayanikr@gmail.com,drparashuram100@yahoo.com

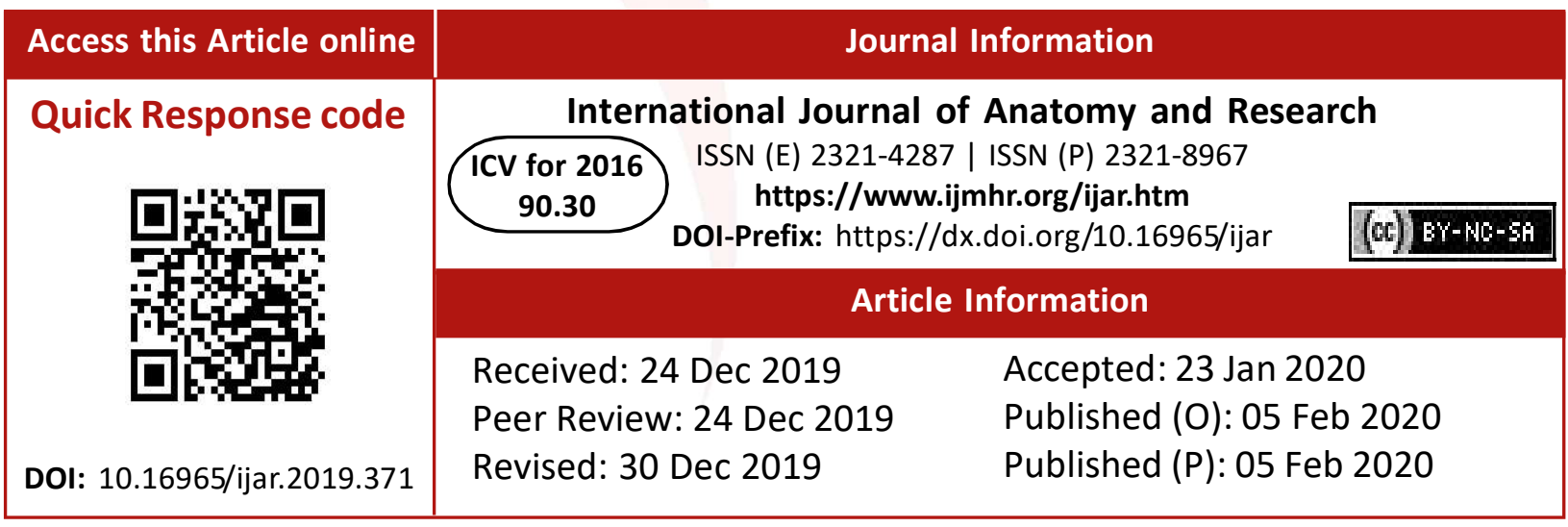

\section{INTRODUCTION}

The word placenta comes from Latin - flat cake and Greek -"Plakous" which means "flat, slab like."[1]. Only eutherian mammals possess placenta. The human placenta is discoid, hemochorial and deciduate which functions as a fetomaternal organ. It is developed from chorion frondosum \& decidua basalis. 
The umbilical cord (also called navel string, birth cord or funiculus umbilicalis) is a conduit between the developing embryo or fetus and the placenta [2].

It is developed from the connective stalk or body stalk which connects the fetus \& the placenta [3].

Abnormalities in the development and site of insertion of the umbilical cord can affect maternal and fetal well-being. It leads to congenital anomaly in fetus and also associated with intra uterine growth retardation (IUGR) and preterm labour.

The umbilical cord is usually attached near the centre of the placenta. It may insert at any point between its centre and margin, a condition known as a battledore placenta (marginal). Occasionally the cord fails to reach the placenta itself and ends in the membranes as a velamentous insertion. In such cases larger branches of the umbilical vessels traverse the membranes before they reach and ramify on the placenta. They travel unprotected through the membranes to the placenta, which puts the fetus at risk because compression or tearing of the vessels can disrupt blood flow to and from the fetus. The cord may branch off before the cord inserts onto the surface of the placenta resulting in a furcate cord insertion [4].

Knowledge about the variations in the placental attachment of umbilical cord is important for Clinical Anatomists, Obstetricians \& Gynaecologists and Radiologists. Hence the present study is carried out to know the variations in the placental attachment of umbilical cord.

Aims and objectives: The present study is undertaken to study various types of placental attachment of umbilical cord: 1) Central 2) Eccentric 3) Battledore (Marginal) 4) Velamentous (Membranous) 5) Furcate.

\section{MATERIALS AND METHODS}

Source of data: The study was carried out on $10 \%$ formalin fixed 100 normal human placenta collected from department of Obstetrics and Gynaecology, Cheluvamba Hospital for children \& women, Mysore medical college and research institute, Mysuru, Karnataka, India.
Study setting: The study was carried out in department of Anatomy, MMC\&RI, Mysuru, Karnataka. Fully normal placenta was included. Damaged, mutilated, deformed placenta was excluded from present study. Study of various types of placental attachment of umbilical cord was done by naked eye observation. The data obtained was tabulated \& statistically analysed.

Study design: It is a descriptive study.

\section{OBSERVATIONS AND RESULTS}

The pattern of placental attachment of umbilical cord was observed in all 100 specimens. Out of 100 specimens, 68 placenta had central attachment of umbilical cord, 16 placenta had eccentric attachment, 12 placenta had battledore (marginal) attachment and 04 placenta had membranous (velamentous) attachment. Furcate type of umbilical cord attachment was not observed in the present study

Fig. 1: Central attachment of umbilical cord

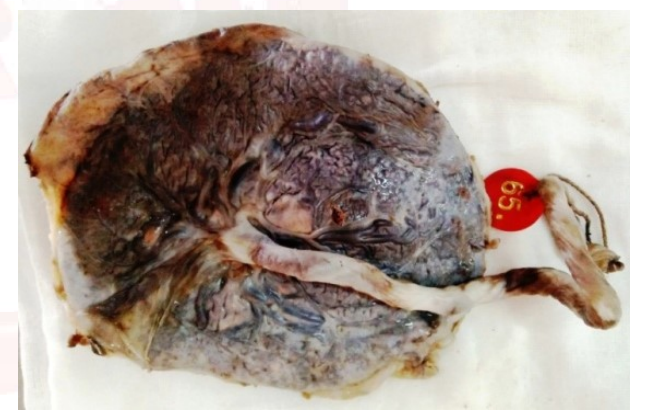

Fig . 2: Eccentric attachment of umbilical cord

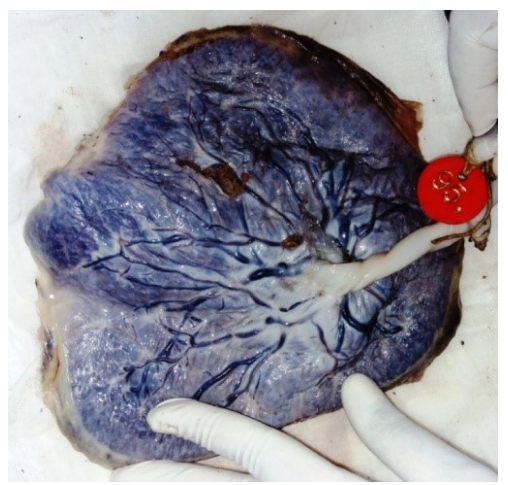

Fig. 3: Battledore attachment of umbilical cord

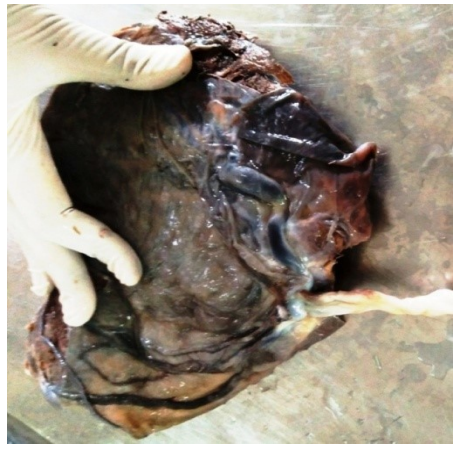


Fig. 4: Velamentous attachment of umbilical cord

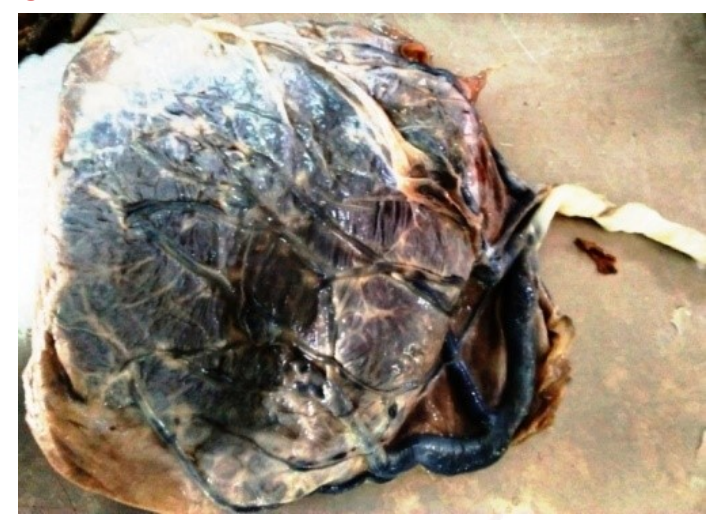

Table 1: Various types of umbilical cord attachment.

\begin{tabular}{|c|c|c|c|}
\hline Sl.no & $\begin{array}{c}\text { Various types of } \\
\text { umbilical cord } \\
\text { attachment }\end{array}$ & $\begin{array}{c}\text { Total no. of } \\
\text { placenta studied } \\
(\mathbf{1 0 0})\end{array}$ & $\begin{array}{c}\text { Percentage } \\
\text { (\%) }\end{array}$ \\
\hline $\mathbf{1}$ & Central & 68 & 68 \\
\hline $\mathbf{2}$ & Eccentric & 16 & 16 \\
\hline $\mathbf{3}$ & Battledore (Marginal) & 12 & 12 \\
\hline $\mathbf{4}$ & $\begin{array}{c}\text { Velamentous } \\
\text { (Membranous) }\end{array}$ & 4 & 4 \\
\hline $\mathbf{5}$ & Furcate & ---- & ---- \\
\hline
\end{tabular}

Pie chart: Proportion of various types of placental attachment of umbilical cord

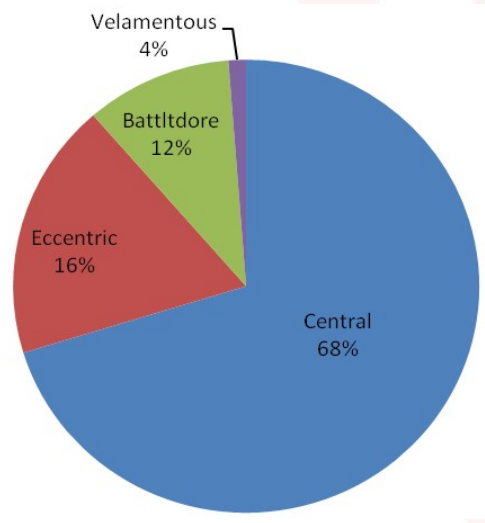

\section{DISCUSSION}

Deformities in the placental attachment of umbilical cord have been associated with complications of pregnancy and poor fetal outcome due to compression of umbilical vessels. These complications are also associated with intrauterine growth retardation (IUGR) and preterm labour.

There can be several variations with umbilical cord insertion (attachment) into the placenta [5]:

Central insertion (90\%): normal situation

Eccentric cord insertion: lateral insertion of the umbilical cord $>2 \mathrm{~cm}$ from the placental margin

Battledore (Marginal) cord insertion (7\%): insertion of the umbilical cord $<2 \mathrm{~cm}$ from the placental margin
Velamentous (Membranous) cord insertion (1\%): insertion of the umbilical cord on the fetal (chorioamniotic) membranes.

Furcate cord insertion: when blood vessels divide before reaching the placenta.

The present study revealed that commonest type of attachment of umbilical cord was Central (68\%), followed by Eccentric (16\%), Battledore (Marginal) $12 \%$ and Velamentous (Membranous) $04 \%$. This finding is almost similar with the findings of Jeyasingh T et al (2006) [6] and Yousuf et al (2015) [7].

Marginal cord insertion and velamentous cord insertions are categorized as abnormal umbilical cord attachment. Velamentous cord insertion occurs in approximately $1 \%$ of singleton pregnancies and Marginal cord insertion in approximately 7\% (2011) [8]. In Velamentous cord insertion, the umbilical vessels are prone to compression and rupture due to the lack of protection from Wharton's jelly (2011) [9]. Velamentous cord insertion is eight times more common in twin than singleton pregnancies, with double the risk with monochorionic twins, and three times the risk in twin pregnancies with fetal growth restriction (2015) [10].

The pathogenesis of the abnormal umbilical cord attachment is not well understood. Three theories have been proposed: 1) The abnormal primary implantation or 'polarity theory', which postulates that umbilical cord insertion site is determined at initial implantation by the orientation of the fetal pole relative to the endometrial surface; 2) The theory of trophotropism which postulates that the placenta grows in areas with good blood supply and atrophies in areas where there is not; 3 ) The "abnormal placental development because of decreased chorionic vessel branching" theory, which posits that non-central insertion results from abnormal vasculogenesis in the placenta (2011) [8]. Advanced maternal age (>35 yrs) was significantly associated with an increased risk of velamentous umbilical cord attachment.

Donald $\mathrm{N}$ et al (1988) [11] conducted a ultrasonographic (USG) study in 46 pregnancies which included 38 singletons and 8 twins for a total of 54 placental umbilical cord attachments. 
Table 2: Comparison of various types of umbilical cord attachment with previous studies.

\begin{tabular}{|c|c|c|c|c|c|c|c|}
\hline Sl.no & Authors & $\begin{array}{c}\text { No of } \\
\text { placenta } \\
\text { studied }\end{array}$ & $\begin{array}{l}\text { Central } \\
(\%)\end{array}$ & $\begin{array}{c}\text { Eccentric } \\
(\%)\end{array}$ & \begin{tabular}{|c|} 
Battledore \\
(Marginal) \\
$(\%)$ \\
\end{tabular} & \begin{tabular}{|c|}
$\begin{array}{c}\text { Velamentous } \\
\text { (Membranous) } \\
(\%)\end{array}$ \\
\end{tabular} & $\begin{array}{l}\text { Furcate } \\
\text { (\%) }\end{array}$ \\
\hline 1 & $\begin{array}{c}\text { Donald N et al [11] } \\
(1988)\end{array}$ & 54 & 70.37 & -- & 22.22 & 7.41 & -- \\
\hline 2 & $\begin{array}{c}\text { Sepulveda W et al [12] } \\
(2003)\end{array}$ & 825 & 93 & -- & 5.21 & 0.96 & -- \\
\hline 3 & $\begin{array}{c}\text { Manikanta R et al [13] } \\
(2012)\end{array}$ & 110 & 75.45 & -- & 16.36 & 0.9 & 7.27 \\
\hline 4 & Yousuf et al [7] (2015) & 150 & 24 & 66 & 2 & 8 & -- \\
\hline 5 & $\begin{array}{c}\text { Shrivastava S et al [14] } \\
\text { (2018) }\end{array}$ & 78 & 32.05 & 57.6 & 8.97 & -- & 1.28 \\
\hline 6 & $\begin{array}{c}\text { Arora NK et al [15] } \\
(2016) \\
\end{array}$ & 32 & 18.75 & 59.38 & 15.62 & 3.12 & 3.12 \\
\hline 7 & $\begin{array}{c}\text { Jeyasingh T et al [6] } \\
(2016) \\
\end{array}$ & 50 & 22 & 70 & 8 & -- & -- \\
\hline 8 & Present study & 100 & 68 & 16 & 12 & 4 & -- \\
\hline
\end{tabular}

They observed 38 (70.37\%) normal attachments, $12(22.22 \%)$ marginal and $4(7.41 \%)$ velamentous attachments, which was almost similar to present study. Sepulveda W et al (2003) [12] conducted a colour Doppler ultrasonographic study in 825 pregnancies and observed 774 (93\%) normal central attachments, $43(5.21 \%)$ marginal attachments and $8(0.96 \%)$ velamentous attachments, which are higher when compared to present study. Furcate type of umbilical cord attachment was not observed in present study but according to study conducted by Manikanta R et al (2012) [13], Shrivastava S et al (2018) [14], and Arora NK et al [15] observed $7.27 \%, 1.28 \%$ and $3.12 \%$ furcate type of umbilical cord attachment respectively.

\section{CONCLUSION}

The present study reveals the variations of human placental attachment of umbilical cord and the most common type was Central (68), followed by Eccentric (16), Battledore (Marginal) 12 and Velamentous (Membranous) 04. Variation in the placental attachment of umbilical cord is associated with various congenital anomalies such as preterm labor, low birth weight, intrauterine growth retardation (IUGR), oesophageal atresia, spina bifida and ventricular septal defect (VSD). Hence this study is useful for all the clinicians for proper diagnosis and treatment of disease. Therefore early prenatal ultrasonographic identification of these anomalies helps in reducing risk in maternal and perinatal outcome.

\section{Conflicts of Interests: None}

\section{REFERENCES}

[1]. https://en.wikipedia.org/wiki/Placenta

[2]. https://en.wikipedia.org/wiki/Umbilical_cord

[3]. Hiralal K. DC Dutta's textbook of Obstetrics. $8^{\text {th }}$ edn. The health sciences publisher, New Delhi, 2016, pp. 32-44.

[4]. Standring S Gray's Anatomy-The Anatomical Basis of Clinical Practice. $40^{\text {th }}$ edn. Churchill Living stone, Elsevier, New York, USA, 2008, pp. 1303

[5]. https://radiopaedia.org/articles/variation-in-cordinsertion

[6]. Jeysingh T, Rohinidevi M, Vimala V. Variations in the placental attachment of umbilical cord and its embryological significance. IOSR Journal of dental and medical sciences, 2016;15(3)7: 101-103

[7]. Yousuf MS, Tarannum Y, Naval KP. Variations in the placental attachment of umbilical cord and its clinical significance. Journal of medical and dental sciences, 2015;4(70):1-7

[8]. Baergen RN. Pathology of the Umbilical Cord. Manual of Pathology of the Human Placenta. $2^{\text {nd }}$ edn, Springer Science \& Business Media, New York, 2011.

[9]. Benirschke K. Manual of pathology of the human placental. $2^{\text {nd }}$ edn. Spinger Science \& Business Media, New York, 2011.

[10]. Hubinont C, Lewi L, Bernard P, Marbaix E, Debieve F, Jauniaux E. Anomalies of the placenta and umbilical cord in twin gestations. Am J Obstet Gynecol. 2015; 213(4):S91-S102.

[11]. Donald N. Di Salvo, Carol B. Benson, Faye C. Laing. Sonographic evaluation of the placental cord insertion site. American journal of radiology 1988; 170: 1295-1298

[12]. Sepulveda W, I. Rojas, J.A. Robert et al. Placental detection of velamentous insertion of umbilical cord: a prospective colour Doppler ultrasound study. Ultrasound Obstet Gynecol, 2003; 21:564569.

[13]. Manikanta R, Geetha S P, Nim V K. Variations in placental attachment of umbilical cord. J. Anat. Soc. India. 2012; 61(1):1-4. 
[14]. Shrivastava S, Mishra B, Sudhakar KR, Shrivastava VK, Shivhare PR. Variation of human placental attachment of umbilical cord. International Journal of Scientific Study. April 2018; 6(1):17-20.

[15]. Arora N K, Khan A Z, Haque M, Srivastava S, Farden Q. Variations in placental attachment of umbilical cord. Annals of International Medical and Dental Research. 2016;2(1):110-12.

How to cite this article:

Dakshayani. K.R, Rajapur. Parashuram. STUDY OF VARIATIONS IN HUMAN PLACENTAL ATTACHMENT OF UMBILICAL CORD AND ITS CLINICAL SIGNIFICANCE. Int J Anat Res 2020;8(1.2):7333-7337. DOI: $10.16965 /$ ijar.2019.371 